\title{
Cartaphilus
}

Revista de investigación y crítica estética

\section{EL ARTE Y LA DESAPROPIACIÓN DEL MUNDO}

ART AND THE DISAPPROPRIATION OF THE WORLD

\section{SERGIO ESPINOSA PROA}

Universidad AutónOMA de ZaCATECAS (MÉXICO)

Resumen: Las obras de arte son objetos materiales que al mismo tiempo y de modos misteriosos son objetos espirituales (a saber: inmateriales). Utilizando a Kant y a Schiller, en este artículo se opone a la calificación platónica y aristotélica una concepción distinta del arte, que sería una manufactura humana no sometida a la lógica de la apropiación, sino de su contraria. El hombre es un ser racional, pero Kant le otorgó tres dimensiones a esta idea: la razón es conocimiento, mas también compasión y contemplación. Un ser humano tiene intereses teóricos, intereses prácticos... y desintereses múltiples. El "temple estético" al que Schiller hace referencia apunta a esta facultad de no hacer nada, a este aflojamiento de las tensiones, ocupaciones y preocupaciones, al puro deleite (o pavor) de estar meramente en el mundo. La experiencia o la emoción estética aflora cuando no esperamos nada - ni bueno ni malo- de las cosas. Es paradójico que una dimensión de nuestra racionalidad sea la facultad de no esperar, de no buscar, de no mo- dificar o sustituir, de no mover un dedo, de simple y llanamente no hacer nada: es la facultad de dejar llegar, de dejar aparecer (y desaparecer), de dejar ser a las cosas; es la facultad de desactivar momentáneamente- nuestras otras facultades.

Abstract: Works of art are material objects that at the same time and in mysterious ways are spiritual objects (i. e. immaterial). Using Kant and Schiller, this article opposes the Platonic and Aristotelian qualification with a different conception of art, which would be a human manufacture not subject to the logic of appropriation, but of its opposite. Man is a rational being, but Kant gave this idea three dimensions: reason is knowledge, but also compassion and contemplation. A human being has theoretical interests, practical interests... and multiple interests. The "aesthetic temper" to which Schiller refers points to this faculty of doing nothing, to this loosening of tensions, occupations and worries, to the pure delight (or dread) 
of being merely in the world. Aesthetic experience or emotion comes to the surface when we expect nothing neither good nor bad- from things. It is paradoxical that one dimension of our rationality is the faculty of not waiting, of not seeking, of not modifying or substituting, of not moving a finger, of simply doing nothing: it is the faculty of letting come, of letting appear (and disappear), of letting things be; it is the faculty of deactivating - momentarilyour other faculties.

Palabras clave: Kant; Schiller; Arte; Desapropiación.

Keywords: Kant; Schiller; Art; Disappropriation.

Las obras de arte son objetos materiales -piedra, aire, color, papel, tela, tinta, hierro, vidrio, gestos, posturas, maderas, plásticos, sonidos, incluso aromas y sabores...- que al mismo tiempo y de modos misteriosos son objetos espirituales (a saber: inmateriales). Es decir, imilagro!, son objetos no objetos, objetos inmediatamente sujetos, objetos evanescentes, sujetos que en su mayor parte no son asequibles por medio alguno. Son una clase muy especial de sujeto/objeto. Incitan a la acumulación, a la colección, a la exhibición - y a la vez a la sustracción de la mirada, a su ocultamiento, a su destrucción y despilfarro. Curan y enferman: son fármacos (en el sentido griego). Mercancías inmunes a la tasación social: mercaderías anómalas. Valen o no valen según azares y arbitrios privados y selectivos. Provocan emociones, disparan ideas, suscitan movimientos. Dan envidia, asombran, molestan, espantan, distraen, marcan, trauman, aligeran, enloquecen. Son fetiches, cosas cargadas de mana, de orenda, de aura, de sosiego, postración y escándalo.

Las obras de arte, perfectamente reales, concretas y objetivas, fingen a morir: la polaridad verdadero/falso les es indiferente. Son la elusión, la alusión, la ilusión materializada. ¿Alcanzan a ser bellas? ¿Horrorizan? ¿Parecen gloriosas? En cualquier caso, conmueven, alteran. Son elementos no naturales que entablan con la naturaleza una amistad extraña y sospechosa; mímesis y desafío, afinidad y desavenencia. Son efectos de goce (en el sentido psicoanalítico). ¡Vaya si merecen y solicitan una consideración filosófica! De hecho, a los filósofos se les dificulta, por bajas o excelentes razones, pensar objeto semejante. Mas lo han ejercitado, y sus productos también - con frecuencia- emocionan; la verdad, ocasionalmente aburren o fastidian. El mundo del arte no termina nunca de cerrarse; le sobra o le falta algo, siempre. Naturalmente, la obra de arte, dado que es inagotable, pide discursos sabios que le hagan justicia; se entrega a la historiografía, a la antropología, a la sociología, a la psicología, a la economía política, a la arqueología, al periodismo e incluso a la literatura. Cada uno articulará, sostendrá y emitirá su opinión. Aquí sólo podremos proponer un recorrido, un sesgo, un desvío más o menos libre. El arte es un enigma, por eso se relaciona con el pensamiento arcaico (y su sensibilidad) y no ha cesado de lanzar retos a la modernidad, tan cansada ya de casi todo. Ni siquiera disponemos de definiciones 
universalmente admitidas; y los métodos propuestos adolecen por fuerza de unilateralidad. Lo que hay, como en el caso de los mitos antiguos, son versiones, escorzos, aristas, ductos, escurrimientos, charcos. Ensayemos pues nuestro itinerario.

En la Crítica del Juicio (1978, pp.102-106), Immanuel Kant presupone, a fin de dirimir conflictos en materia de gustos, que existen dos clases de belleza: una, sensible, natural, espontánea, libre, pura; otra, intelectual, artificiosa, condicionada, interesada, impura. Ambas son legítimas, pero no es aconsejable confundirlas. La belleza pura (pulchritudo vaga) lo es porque sí, sin ajustarse a fin o propósito alguno: sin concepto. La impura, que lo es por ser humana, se aplica se adhiere, se añade - a sus obras: es bello lo que se ajusta a su finalidad y contribuye a alcanzarla. Belleza pura, pues, es belleza sin fin, sin propósito, sin uso, sin intención; es bello, en su indiferencia práctica (o moral), aquello que meramente place y complace. La belleza pura no es humana: ni significa ni representa nada, sólo se contenta con ser. No es humana porque no se pliega a sus necesidades, a fines previamente definidos; puede incluso ser hecha por nosotros, pero, como la música desprovista de palabras, o de "temas", no sirve para nada. Que sirva, que se adapte a una necesidad humana, terminará dañando a las cosas bellas. La belleza, dice Kant, es sin concepto. En consecuencia, no hay reglas que aplicar al gusto: cada quien posee su propio criterio y su propio patrón de medida. Las reglas solamente aplican cuando la belleza está sojuzgada por otra cosa y es dependiente de ella; cuando algo es bello porque es bueno o útil, conveniente o funcional, oportuno o accesible. "Pero, propiamente", observa el filósofo, "ni la perfección gana por la belleza ni la belleza por la perfección"; no, pero la representación - el pensamiento- sí. Lo interesante aquí es, desde luego, el reconocimiento de la superioridad de la belleza sensible respecto de la inteligible; Kant, sin mencionarlo expresamente, se aleja de Platón, que pensaba, al rebajar cuanto pudo la dimensión de lo sensible, y al despreciarlo, exactamente todo lo contrario.

También Friedrich Schiller, en La educación estética del hombre, saldrá en defensa de las bondades de lo sensorial: la virtud de la belleza es obligarnos a pensar y, a quien ya lo hace, invitarlo a descender de su altura al "trato con la materia y el mundo sensible" (2012, p. 86). La belleza actúa como puente, como enlace entre ambos "mundos". Claro que para Schiller esta función resulta sumamente problemática; todo indica que no hay paso entre el sentimiento y la razón, que se abre una distancia infinita entre la experiencia y lo pensable. No es asunto de tomar partido; el adepto de la inteligencia se extravía tanto o más que el del poder de los sentidos: "(...) el hombre que aún no ha comenzado a filosofar está más cerca de la verdad que el filósofo que aún no ha terminado su investigación" (p. 88n.). Más cerca, pero nunca en posesión de ella; la verdad no se entrega a los extremos, sino a la razón, responsable de su unificación. Seguramente, pero ¿qué es la razón? ¿Una causa, o un efecto? ¿Un principio o una meta? ¿Un instrumento neutro? ¿Es primariamente entendimiento, o es sensibilidad? Schiller adelanta la hipótesis romántica por excelencia: la razón no es una facul- 
tad, sino el estado ideal de equilibrio entre el sentimiento y la inteligencia, es decir, entre la pasión y la acción, la seriedad y el juego, el reposo y el movimiento, la aquiescencia y el rechazo, el instinto y el "pensamiento absoluto". Equilibrio alcanzado precisamente por el "temple estético", cuyo valor "tiende a cero": sólo así es factible elevar lo particular a la universalidad, sólo así se vence toda limitación -que es por cierto el cometido de la razón. Con esto, el equilibrio, a pesar de Schiller, se rompe: la obra de arte consiste en la aniquilación de la materia (o del contenido) por la forma. De poco servirá la asimilación de la razón al temple estético. ¡Platón de nuevo a la vista!

La posición de Kant ha resultado casi inexpugnable; sus tres Críticas marcan profundamente el territorio filosófico de la modernidad. El hombre es sin duda, para el talante ilustrado, un ser (un animal) racional, pero Kant le otorgó tres dimensiones a esta idea: la razón es conocimiento, mas también compasión y contemplación. Un ser humano tiene intereses teóricos, intereses prácticos... y desintereses múltiples. El "temple estético" al que Schiller hace referencia apunta a esta facultad de no hacer nada, a este aflojamiento de las tensiones, ocupaciones y preocupaciones, al puro deleite (o pavor) de estar meramente en el mundo. La experiencia o la emoción estética aflora cuando no esperamos nada -ni bueno ni malo- de las cosas. Quizá ello explique lo maravillosa que suena la música cuando, en la duermevela, no estamos ni dormidos ni despiertos: es el "punto cero", la hora crepuscular o auroral de nuestras facultades. Es paradójico que una dimensión de nuestra racionalidad sea la facultad de no esperar, de no buscar, de no modificar o sustituir, de no mover un dedo, de simple y llanamente no hacer nada: es la facultad de dejar llegar, de dejar aparecer (y desaparecer), de dejar ser a las cosas; es la facultad de desactivar - momentáneamentenuestras otras facultades. Hay quien no duda en llamar a este estado "beatitud"; si no esperamos nada, todo cuanto comparece es prodigioso en su gratuidad. Es obvio que nadie puede vivir de aire: responder a necesidades de tipo cognoscitivo y sujetarse a normas morales o civiles también forma parte de lo que esencial y no accidentalmente somos; pero el efecto de la elaboración kantiana, su resultado más atractivo, es la convicción de que sólo en el temple o estado estético estamos en presencia de lo real: es cuando el objeto cesa de ser un medio, una herramienta o un arma para aparecer en su inocencia y en su soberanía absolutas.

Este descubrimiento llega intacto a Heidegger, que extraerá las debidas consecuencias. ¡Lo único verdaderamente ético es lo estético! Sí, porque Kant y la mayoría de los ilustrados piensan que el mal es la inclinación al egoísmo, la conversión de todo cuanto existe en medio de satisfacción de necesidades (individuales o grupales o nacionales), manía que sólo la contemplación estética bloquea o suspende. ¡Ni siquiera la religión, comprometida o enfangada en su anhelo de salvación, tiene el poder de lograrlo! El temple estético consiste en anular la voluntad de apropiación y en experimentar la simpatía por todo lo que existe. A tal modo de percibir el mundo y estar en él Kant le llamará "intuición" o "reflexión", a fin de no confundirlo con el concepto (teórico) ni con la norma (moral). 
En la intuición, lo único que importa es afirmar la existencia (o inexistencia) del objeto, que si ha dejado de concebirse como medio ya ha perdido su carácter de objeto. Suspender la inclinación egoísta significa no aniquilar o extinguir el deseo a la manera budista, sino abrirlo a posibilidades distintas: ni la posesión ni el rechazo, ni la voracidad ni el asco. Si según Kant existe en nosotros una facultad de no hacer nada, ¿por qué no admitir, sin orientalizarnos con coquetería New Age, un deseo de no desear? Después de todo, que en la edad moderna predomine el deseo de apropiación y usufructo no autoriza a pensar que sólo ese deseo, desde el origen hasta el fin de los tiempos, nos movilice.

"La parte que confía en la medición y en el cálculo ha de ser la mejor del alma" (603a). No "es": ha de ser, debe ser. Tenemos que releer las páginas de la República donde Platón justifica el destierro de los poetas trágicos: en el fondo exhibe la perversidad del arte y su índole nociva respecto de una ciudad bien gobernada. Antes del libro X, ya ha arremetido contra Homero, contra la música y contra Eurípides; de este último habrá dicho que es un "cantor de la tiranía" (568b). Que el empeño de Platón es político nadie lo pondrá en duda: condenará a la tragedia por sus efectos "ideológicos", que considera desastrosos. Porque, en primer lugar, el arte es "mimético", una imitación de tercer nivel -es copia de una copia del original- que se coloca "a triple distancia del ser"; la pintura y la poesía son una celebración de lo aparente, nunca de lo real. "Todos los poetas, empezando por Homero, son imitadores de imágenes de virtud", y en cuanto tales sólo añaden una capa de maquillaje al verdadero rostro de las cosas: son perfectamente superfluos, es decir, superficiales. De las tres "artes" —utilización, fabricación e imitación - la última es naturalmente inferior; no tiene seriedad, es una "niñería" (602b). El arte, como imitación o como reproducción de algo previamente existente, es un juego, una trivialidad - pero una banalidad o una ingenuidad peligrosa: pues mantiene una "amistad" con la parte de cada uno que más se aleja de la razón, con la parte maldita y salvaje, con lo más "vil" de nosotros mismos. "Y así, cosa vil ayuntada a cosa vil, sólo lo vil es engendrado por el arte imitativo" (603b). Así que es un juego de niños, pero jamás exento de perversidad.

Así aparecen las cosas para un animal político, para una bestia en doma, para un espíritu ilustrado: porque sólo aquello "que da fe a la medida y al cálculo" constituirá "lo mejor de nuestra alma". El empeño de Platón, recuérdese, es político: sabe que los humanos somos seres compuestos (es decir: nos descomponemos), y que, por consiguiente, requerimos de un amo: ¿quién tiene derecho a regir en nuestra República interior si no la razón, eso que "da fe a la medida y al cálculo"? El poeta (trágico) se remite por contra a otro amo: al Agón, a la lucha interior, al conflicto incesante. No al cálculo y la medida, sino a la ambigüedad y la autocontradicción (603d). La equiparación de la razón con la Ley es total: sólo la primera puede plegarse a la segunda. Podrá parecernos excesivo su examen, y nefasto el tratamiento sugerido, pero Platón, para no variar, da en el clavo: la filosofía es política, el arte... El arte es expresión de una desobediencia constitutiva, de una rebeldía inerradicable: es lo impolítico. La razón es sujeción a la Ley, 
el arte es remisión y resistencia; el poeta da voz al "elemento irritable y multiforme" de cada individuo, gesto que no tendría nada de malo si no fuera porque, al mimarlo, al fortalecerlo, "acaba con la razón" y termina instaurando "un régimen perverso en el alma de cada uno condescendiendo con el elemento irracional que hay en ella" (605b, c). Algunos traducen "congraciándose"; sea como fuere, Platón da forma a la filosofía como un arte de sujeción de la parte fluida y caótica, de la dimensión insensata y libre del alma. Con ella, si el propósito es político, no procede ni amistad ni condescendencia ni complicidad alguna: la poesía "riega y nutre en nuestro interior lo que había que dejar secar y erige como gobernante lo que debería ser gobernado" (606d). Juicio tan implacable cuya implantación sólo podría garantizarse mediante un régimen de rigurosa censura. De "juego de niños", el arte se ha transformado en amenaza de tiranía: de darle cabida en la ciudad, reinarán "el placer y el dolor en vez de la Ley y de aquel razonamiento que en cada caso parezca mejor a la comunidad" (607a). La secularización de la justicia se halla aquí cumplida en su integridad; la poesía -es decir, la tragedia, el arte- pertenece, según el fundador de la filosofía, a un estrato anacrónico del mundo y rinde tributo a los espíritus de la tierra. iTiene absoluta razón!

El arte no está al servicio de la parte indómita del alma; es su amigo, lo cual significa que no le hace los mandados, y que por lo mismo puede influir en ella. Que una relación no de gobierno sino de respeto y mutuo aprendizaje es posible lo prueba la historia entera del arte (y de su crítica). Algo de ello se va abriendo paso ya desde Aristóteles, que sin embargo es un intelectual regularmente insoportable: como su maestro, cree a ciegas que "la medida y el cálculo" son la mejor y más noble parte del alma; a ella — no se siente obligado a decir por qué-corresponde la posición y la función del Amo. En consecuencia, somete a la poesía - que como es obvio no se reduce a la mera versificación o métrica- a un tratamiento científico. El arte es arte de la forma, es decir, la capacidad de deformar, reformar y conformar un contenido dado: todo es, en el arte, mímesis, reproducción, representación, imitación, repetición, remedo. El arte no crea ni inventa nada: es un suplemento, un accesorio, un afeite; una ocupación casi completamente prescindible.

Al menos es de lo que Platón quiso convencer a sus contemporáneos, cosa que sin duda logró con su más brillante alumno. Con Aristóteles, empero, el valor disruptivo del arte se encuentra en el nivel más bajo; sigue siendo "cosa de niños", pero desprovisto de su componente amenazante, de su aguijón letal. Al contrario, ya en el estagirita el arte se pone al servicio de buenos propósitos: por ejemplo, hacer agradable lo que naturalmente repugna: "Las formas de las más despreciables fieras, y de los muertos" (2014, cap. 4). La poética posee así virtudes pedagógicas; hace agradable el aprendizaje, que se apoya en semejanzas y exageraciones, en eso que hoy llamaríamos caricaturas: 
No sólo a los filósofos les resulta superlativamente agradable aprender, sino igualmente a todos los demás hombres, aunque participen éstos de tal placer por breve tiempo. Y por esto precisamente se complacen en la contemplación de semejanzas, porque, mediante tal contemplación, les sobreviene el aprender y razonar sobre qué es cada cosa" (2014, cap. 4).

Pero lo propio y característico del arte es, en rigor, el ritmo y la improvisación. Que sea mimético no equivale a declarar que sea inferior, porque puede imitar o mimar -es el sentido del himno- los valores más altos. Cabrá distinguir entonces entre lo cómico, lo épico, lo trágico y lo yámbico: formas más o menos acabadas de remedar lo noble, lo grave, lo vulgar y lo risible. La tragedia evolucionó según esto desde lo satírico - los cantos fálicos - hasta una solemne majestuosidad, descubriendo paulatinamente un ritmo y una armonía más ajustados a su finalidad última. Con todo, a diferencia de su mentor, Aristóteles ya no le teme; incluso le aburre. Es un "objeto" en un sentido prácticamente académico: tema de tesis, materia arqueológica: una momia cultural. El tratamiento aristotélico de aquello que nosotros reconocemos como arte es aséptico, frío, distante, metódico... De ahí su actualidad, su utilidad -y su mediocridad.

La de Aristóteles es, pues, una consideración técnica, una aproximación diríase moderna a la obra de arte; ¿es posible ir más lejos? Quizá no; tal vez se ha hecho imperativo volver sobre sus pasos, emprender otras excursiones, demorarse en ciertos detalles, repensarlo todo. Las obras de arte son como plantas o insectos, sí, pero, al ser productos de la actividad de los hombres, reservan aún multitud de plegamientos, de espacios por llenar, de sorpresas: su presunto carácter ornamental o suplementario da mucho que pensar. En la modernidad, Kant se hizo eco de esta inquietud; hay algo en el juego de las formas que exige un pensamiento adecuado, que pide, junto al conocimiento (calculante) y la piedad (por el sufrimiento ajeno) una crítica específica. iUna critica, no una ciencia! Porque una cosa es la belleza - pura o impura, vaga o añadida-, pero otra la obra, que parecería a veces darle lugar a lo reprimido por la razón (y por su sometimiento a la Ley). La obra es un objeto, desde luego; pero no es un objeto como el resto. Para captar su especificidad, Kant saca y aplica el cutter: no es bueno confundirla con la naturaleza - porque es producto de la reflexión, es decir, de la libertad, no del instinto-; ni con la técnica - porque no se crea sólo para satisfacer necesidades previamente sentidas-; ni con el oficio - dado que el propósito de la obra no es obtener beneficios para ganarse la vida-: la obra no es efecto de violencia alguna.

Producto de la libertad, es decir, de un estado-cero de la necesidad o de la constricción. Por similares razones es justo distinguir entre goce sensual, o puramente sensorial (Kant pone el ejemplo de la buena mesa), y goce intelectual o reflexivo, cuya meta es la cultura: el cultivo, el cuidado, el crecimiento de las facultades del espíritu que sin siquiera pretenderlo impactan en la vida común. Una vez más: sin experiencia estética no hay ética imaginable. El arte -la obra- 
abre la posibilidad de que algo tan íntimo como el goce sea compartible, comunicable, inmediatamente social. Y ello a pesar de que la belleza es siempre de otro mundo - un guiño, una señal de lo otro del mundo. Decisivo es, para Kant, entender que la obra de arte sólo existe como expresión de la libertad, pero no en su restrictivo sentido teológico: una manifestación humana despojada de toda violencia, humana o inhumana. Conocer es violento, someterse al imperativo categórico es violento; ponerse en manos de la obra suspende, revierte, interrumpe toda violencia, sea natural o sea moral, sea externa o sea interna. "En un producto del arte bello", anota en la Crítica del Juicio, "hay que tomar conciencia de que es arte y no naturaleza; sin embargo, la finalidad en la forma del mismo debe parecer tan libre de toda violencia de reglas caprichosas como si fuera un producto de la mera naturaleza. En ese sentimiento de la libertad en el juego de nuestras facultades de conocer, que al mismo tiempo debe ser, sin embargo, conforme a fin, descansa aquel placer que sólo es universalmente comunicable, sin fundarse, sin embargo, en conceptos. La naturaleza era bella cuando al mismo tiempo parecía ser arte, y el arte no puede llamarse bello más que cuando, teniendo conciencia de que es arte, sin embargo parece naturaleza" (prgrf. 45). Es arte si no lo parece, y es bello si no lo pretende: en la obra el máximo esfuerzo está presente, pero esfumándose.

Quién sabe hasta qué grado Aristóteles, pero Kant da la impresión de no ser un ilustrado ingenuo. Se apostará por la razón contra la locura y por el saber frente a la ignorancia, decisión cuya primera condición es plantarse con la máxima honestidad y el mayor valor ante personajes de aspecto tan severo. Platón y Aristóteles dieron el ejemplo sin poder vaticinar lo que con el tiempo saldría de esa caja de Pandora, de ese cofre funesto: Goya, un poco más de un par de milenios después, levantará, en vena eminentemente estética, las correspondientes actas (sobre todo de defunción). Pero lo hará porque Kant trazó las coordenadas e intuyó el continente que desde sus ventanas se alzaba de entre la neblina. El de Königsberg le vio su lado siniestro a la razón, y no quiso ni cerrar los ojos ni mirar a otro lado: la razón no sólo tiene límites (absolutos), sino que se ha revelado como aquello que ostenta y esgrime el derecho de imponérselos a la realidad en cuanto tal. ¿Se lo ha ganado? Nos agrade o no, nos agreda o no, esta pregunta es formulada por la lucidez, no por la razón. Sea como fuere, es perentorio responder, y una de las empresas más impresionantes, por su ambición, por su profundidad y alcance, es la filosofía de Hegel. ¿Cómo se concibe el arte desde ella?

Por principio, habrá que despejar la duda a propósito de la existencia o inexistencia de su objeto; no vaya a ser que edifiquemos una teología para probar que Dios está en el mundo como la sal en los océanos o como una subpartícula perdida entre las galaxias. Es preciso descontar que la belleza existe independientemente de mi percepción; de lo contrario, nuestra especulación será vacía. Hegel es de entrada lo bastante hábil como para cambiar de mano los naipes: la belleza existe objetivamente... pero sólo en la obra de arte. La naturaleza no es ni bella ni carente de belleza: es lo que es, y lo es tal cual porque no es producto de la voluntad o de la acción de los hombres. Lo primero es, pues, re- 
ducir el círculo: la belleza se predica de ciertas cosas que hacen los hombres, es un atributo o una adjudicación: resultado de un juicio. Pero no de un juicio arbitrario, efecto del azar o del capricho; de serlo, la filosofía no tendría nada que decir. iY estamos viendo que dice tal vez demasiado! Hegel es tan hábil que parece que siempre está haciendo trampa. Para justificar que la belleza sólo es verdadera como producto humano se verá obligado a cumplir y hacer cumplir tres reglas (derivadas en parte de Kant y en parte a él contrapuestas): 1) Es artificial (o espiritual), nunca natural; 2) Se dirige al hombre y a nadie más, y 3) Bajo la forma estética, tiene su fin en sí misma. Artificial, humana y autotélica; tales son sus determinaciones. Si con Kant la belleza parecía convocar o echar mano de un elemento no enteramente racional, nítidamente manifiesto en la experiencia de lo sublime, con Hegel ese pasaje se encontrará cegado. Dios sólo es Dios en el Hombre, es decir, en el devenir de la conciencia:

Dios es espíritu y, por consecuencia, el hombre es su verdadero intermediario y su órgano. En la naturaleza, el medio por el que Dios se revela es de existencia puramente exterior. Lo que no se sabe a sí mismo es más inferior en dignidad que lo consciente (Madrid, p. 37).

El "genio" mantiene su trono, pero no es nada sin experiencia y sin destreza: sin trabajo. Por eso no hay una belleza "cósmica"; es objetiva, pero no natural: es, por el contrario, resultado de su superación, efecto de esa re-flexión, de esa interiorización, plegamiento o invaginación infinita que es el espíritu. ¡Poderoso razonamiento!

El arte no es, a juicio de Hegel, ni imitación — sería tonto e inútil copiar lo que ya hay- ni expresión - sería imposible eludir la arbitrariedad, la contingencia y el capricho del individuo-: es creación, invención, novedad absoluta. En esa exacta medida, testimonio del espíritu ante el espíritu. El lenguaje aquí empleado es flagrantemente teológico; pero se admite en general que lo de Hegel es, en buen cristiano, un antropo-teísmo militante. Decisivo es, por lo demás, y en términos filosóficos, el desplazamiento al que somete al sujeto trascendental kantiano: el héroe es el espíritu - que llega a ser siempre en su comunidad. El propietario burgués da desde aquí hasta un poco de pena. En verdad es difícil diferir de su posición básica: lo bello existe, existe objetivamente. Hegel sale al paso de la inclinación relativista (y empirista) que reduce la experiencia estética a un sentimiento o a una mera fruición.

Desde hace mucho tiempo nadie espera gran cosa del arte. El público -o buena parte de él- se ha habituado a las agresiones, a las provocaciones, a las poses rupturistas, a las ofensas deliberadas: el shock es una antigualla, una especie de tic nervioso que no estremece ni a los desprevenidos. Estamos viviendo acaso los últimos coletazos del Ancien règime, herido de muerte por bayonetas y guillotinas y hoy día rematado por misiles satánicos y espectrales dromedarios. Decir que somos posmodernos afecta más al sustantivo que al adjetivo: creer 
que se sigue siendo algo es desmesurada pretensión. La identificación con los desechos tiene ya rato provocando bostezos: unos pocos estornudan para desviar la mirada. El arte denuncia su propia impotencia, su propia irrisión como foro de denuncias. Los artistas, mitad serios mitad jocundos, afirman que "últimamente" el futuro no está entre sus planes. Se diría que tampoco figuran ni el pasado ni el presente. Cuando todo es banal, nada es banal. Cuando todo es suciedad, nada es realmente sucio. Cuando nada tiene sentido, cualquier cosa adquiere significado. No la desfiguración voluntaria sino la descomposición y la decadencia natural alcanzan títulos fascinantes - - o anodinos. Y bien, eso se sabe. Es el pan nuestro. El futuro, en efecto, últimamente no está en los planes de ninguna persona (sensata). ¡No estamos tan locos ni tan enfermos para perder el tiempo de ese modo inicuo! ¿O sí?

Lo único que podemos decir a tal respecto es que hay dos "tonalidades elementales" - una dominante, otra subordinada - que en la modernidad, o en las vanguardias de finales del siglo XIX y principios del XX, hace una irrupción de enorme alcance e impredecibles consecuencias. Existe una sabiduría del arte, que en términos generales parecería coincidir con la sabiduría trágica; ella se opone a la sabiduría técnica en multitud de aspectos: en lo esencial, no intenta apoderarse de las cosas, ni predecir conductas, ni aprovecharse de su energía. La sabiduría trágica, como - entre nosotros- pensó Wittgenstein, deja al mundo tal como es. Ni lo bendice ni lo maldice; sólo, con suerte y tesón, lo dice. Tampoco lo contradice. Quizás, pero ¿cómo, sin olvidarlo, decirlo? El arte es la sabiduría de lo sensible. $Y$ no porque niegue lo inteligible, sino porque evita que éste lo anule o lo instrumentalice. Lo sensible (material) no desmonta el sentido (inteligible); sólo traba su tracto digestivo. El arte, como la filosofía, es trágico -o no es arte. Tal vez, pero ¿en qué sentido lo es? ¿Coincide exactamente con su perspectiva? Hippolyte Taine, a caballo entre el romanticismo y el positivismo, o entre Hegel y Comte, sostiene una tesis un tanto extraña sobre la supervivencia del arte. Dicho en pocas palabras, el arte (o la palabra poética) es el lugar en que el espíritu humano se encuentra en condiciones de descubrir las esencias, los rasgos decisivos o definitorios de las cosas. Si esto fuese así, ¿qué espacio tendría reservada la filosofía en general, y la escritura (como manifestación de lo que llamamos "arte") en particular? Ninguno, a no ser que ella misma ceda su sitio a la ciencia. Porque las obras de arte pueden ser descifradas sólo si se echa mano de metáforas botánicas: ihay arte si hay un invernadero! La estética del idealismo alemán representa, a no dudarlo, una cima insuperable de la reflexión. Hay desde luego otras elevaciones, pero parten de un terreno completamente distinto. Schopenhauer y Nietzsche se oponen frontalmente a Hegel, aunque con Schelling las concordancias pueden ser numerosas. En cualquier caso, Schopenhauer y Nietzsche rechazan con energía $-y$, no pocas veces, con violencia- la consideración dialéctica del mundo que, según sospechamos, reposa en cierta manipulación conceptual de la preposición "en". La dialéctica de Hegel es una secularización - parcial- del mito cristiano - o, más específicamente, paulinode la Encarnación, Muerte y Resurrección del Absoluto. Que la Idea se encuentre 
en lo sensible es lo que, según acabamos de decir, permite distinguir una obra de arte de un artefacto técnico. Lo técnico es una extensión de la naturaleza mientras que lo estético, poético o artístico es una expresión del espíritu. Y el espíritu no está "en" la naturaleza, que es lo inmediatamente dado, sino "en" su "comunidad".

En cuanto comunidad política, el espíritu consiste precisamente en liberarse de la naturaleza, en "superarla". Lo estético es ético: de ninguna manera "imita" a la naturaleza ni se confunde con ella; lo estético es ético porque y en la medida en que designa el movimiento de ascensión o elevación de lo humano desde la animalidad "natural" hacia la comunidad "espiritual". Este movimiento de emancipación de lo humano respecto de la naturaleza es "ideal" en el doble sentido del término: se halla regido, comandado por la Idea, y constituye, por el otro lado, un ideal que moviliza y justifica las acciones de los hombres. Y es en tal virtud que el arte (lo poético) ha de ser concebido como un momento o una fase del movimiento general de emancipación de la naturaleza, y no como una manifestación o un perfeccionamiento de la misma. Situados en esta plataforma, el arte no alcanza un carácter sustancial; no existe la menor posibilidad de esbozar una ontología del objeto estético. El arte y la religión son cristalizaciones momentáneas, transitorias, de lo único sustancial, que (ya se ha decidido) es el espíritu. El arte (y la religión) son epifenómenos, es decir, formas que nunca se ajustan enteramente a su contenido, porque este contenido no es otro que la producción, utilización, consumo y aniquilación de las formas. Dicho en lengua teológica: Dios encarna en forma humana a fin de "probar" la muerte. En (justa) compensación, el hombre es "tocado" por lo divino haciendo de la muerte un paso. Estos son, en su formulación más "económica", los pasos de danza de la lógica mito-lógica de la revelación cristiana. No habría ninguna necesidad de poner en duda que este mito tenga justificación moral o política, e incluso estética, pero, ¿es filosofía? El idealismo alemán es una forma o un modo de filosofar que no puede (quizá ni siquiera quiere) disimular su ascendencia y su textura religiosa: el cristianismo es su motor $-\mathrm{y}$ su combustible. ¿Hasta cuándo le alcanzará? No es cuestión de refutarlo, pero sí en cambio de preguntar si existe a propósito de nuestro problema una formulación verdaderamente filosófica, es decir, la que emerge de una filosofía que no deje de cuestionar las pretensiones de una verdad revelada: desde la filosofía. Y, ¿cuál podría ser ésta, si no lo trágico? 


\section{BIBLIOGRAFÍA}

ARISTÓTELES (2014): Poética. Madrid: Gredos.

HEGEL, G. W. F. (1996): Lecciones de Estética. Madrid: Akal.

KANT, Immanuel (1978): Crítica del Juicio. Buenos Aires: Losada.

PLATÓN (2014): República. Madrid: Gredos.

SCHILLER, Friedrich (2012): La educación estética del hombre. Madrid: Acantilado. 